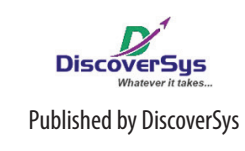

Published by DiscoverSys

\section{Sexual behaviours and sexual networks of men who have sex with men in Bali}

\author{
Ni Luh Dea Kumala Sari Karang, ${ }^{1 *}$ Dewa Nyoman Wirawan, ${ }^{2,3}$ \\ Anak Agung Sagung Sawitri ${ }^{2,3}$
}

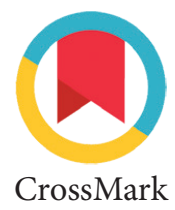

CrossMark

\section{ABSTRACT}

Background and purpose: Transmission of HIV and other sexually transmitted infections (STIs) among men who have sex with men (MSM) in Bali Province is increasing. This increased transmission is due to their sexual networks and behaviours. This study aims to examine sexual behaviours and sexual networks among MSM population in Bali Province. Methods: A descriptive cross-sectional study was conducted in Denpasar City and Badung District. A total of 130 MSM were recruited from Denpasar II Public Health Centre and Bali Medica Clinic - Badung District. Data were collected through interviews among MSM who visited both providers for STIs services from August to October 2015. Variables of this study included sociodemographic, sexual network (pattern and density), sexual activities in the last month, sexual role, condom/lubricant use, and history of previous STIs. Data were descriptively analysed.

Results: As many as $53.1 \%$ respondents were aged $<25$ years, $90.8 \%$ were senior high school or higher degree graduates, $6.2 \%$ were married, $91.5 \%$ were employed, and $59.2 \%$ were having a regular partner. In the last month, as many as $70.8 \%$ respondents reported to have sex with first sexual partner, $52.3 \%$ with second sexual partners, and $45.6 \%$ with third sexual partners. Younger respondents tended to seek for younger sexual partners. The majority of respondents had had insertive sex, as many as $40.0 \%$ with their first partner, $44.6 \%$ with their second partner, and $43.2 \%$ with their third partner. About 20\% of respondents were having high density sexual network and $71.5 \%$ of respondents were having concurrent sexual partnership. The consistent condom use within six months was $67.6 \%$ with the first partner, $72.8 \%$ with the second and the third partners. As many as $23 \%$ of respondents were diagnosed to have STls.

Conclusion: MSM population in Bali Province seem to have high risk sexual behaviours with great sexual network density, high concurrent sexual partnership, and selective mixing between older and younger MSM population.

Key words: sexual behaviours, sexual networks, MSM, Bali

Cite This Article: Karang, N.L.D.K.S., Wirawan, D.N., Sawitri, A.A.S. 2017. Sexual behaviours and sexual networks of men who have sex with men in Bali. Public Health and Preventive Medicine Archive 5(1): 72-76. D01:10.15562/phpma.v5i1.47

'Denpasar City AIDS Commission, ${ }^{2}$ Public Health Postgraduate Program Faculty of Medicine Udayana University,

${ }^{3}$ Department of Community and Preventice Medicine Faculty of Medicine Udayana University

${ }^{*}$ Correspondence to: Ni Luh Dea Kumala Sari Karang, Denpasar City AIDS Commission deakarang@yahoo.com

\section{INTRODUCTION}

The estimated number of men who have sex with men (MSM) in Indonesia was 1.2 million people and around 14 thousands for Bali Province. ${ }^{1}$ Findings from the 2007 and 2011 Integrated Behaviour and Biological Survey (IBBS) showed that HIV and syphilis prevalence among MSM in several cities in Indonesia were significantly increased. $^{2}$ HIV prevalence in Jakarta among MSM population was increased from $8.1 \%$ in 2007 to $17.2 \%$ in $2011 .^{2}$ Similarly, HIV prevalence in Bandung City was increased from $2.0 \%$ to 10.4\% between 2007 and $2011 .^{2}$ In Surabaya City, between 2007 and 2011, the HIV prevalence was increased from $5.6 \%$ to $9.6 \% .^{2}$ Similar trend was also observed for syphilis prevalence. Between 2007 and 2011, syphilis prevalence in Jakarta City was increased from $3.2 \%$ to $16.8 \%$, in Bandung City was increased from $5.6 \%$ to $11.2 \%$ and in Surabaya City was increased from $4.0 \%$ to $9.6 \%{ }^{2}$ Data from Amerta Clinic - Kerti Praja Foundation showed that from a total of 814 MSM who accessed HIV counselling and testing service between April and December 2016, as many as 104 MSM (12.8\%) were HIV positive and between January and June 2017, 98 MSM (12.6\%) out of 772 MSM were HIV positive. $^{3}$

The risk for HIV and other sexually transmitted infections (STIs) is associated to sexual behaviours, patterns and sexual networks among MSM. ${ }^{4}$ A study in China revealed that the high prevalence of HIV and STIs among MSM population were associated to number of sexual partner, anal sex behaviours, receptive partner, and high density sexual networks which contribute to HIV transmission. ${ }^{4}$ Sexual behaviours among MSM are indirectly related to risk of HIV transmission which possibly attributed by their sexual networks. ${ }^{5}$ Another study on sexual networks of MSM in Yogyakarta, Indonesia revealed that a total of 131 sexual networks existed with average age of 23 years and the majority of HIV positive respondents had sex with more than one sexual partners. ${ }^{6}$ This study aims to examine sexual networks (density, patterns, and selective mixing) and sexual behaviours (sexual role, condom/ 
lubricant use, sex in the last month, and history of STIs) among MSM population in Bali Province.

\section{METHODS}

A descriptive cross-sectional study was conducted in Denpasar City and Badung District. A total of 130 MSM were recruited to participate in the study. Data were collected through interviews among those who accessed STIs services at Denpasar II Public Health Centre and Bali Medica Clinic in Badung District. Data were collected from August to November 2015. The inclusion criteria included men who have sex with men at least one time in the last year, agree to participate in the study by signing up the informed consent, and agree to be tested for STIs. Data were collected by a midwife at the Denpasar II Public Health Centre and a counsellor at the Bali Medica Clinic. Research variables included sociodemographic, sexual networks, and sexual behaviours. Sociodemographic characteristics included age, employment status, marital status, and education. Sexual behaviours included sexual role, condom and lubricant use, and sexual intercourse in the last month with a maximum of three sexual partners. Data on sexual networks included density and patterns of sexual partnership. Sexual density was defined as a total of sexual partnership between respondents and their sexual partners in the last year. Sexual partnership pattern was defined as period of sexual partnership between respondents and their sexual partner over the last year which included concurrent and monogamous partnership.

\section{RESULTS}

A total of $53 \%$ of respondents were interviewed at the Bali Medica Clinic, Badung District, while another $47 \%$ were at Denpasar II Public Health Centre. Sociodemographic characteristics of respondents can be seen in Table 1. As many as $53.1 \%$ of respondents were aged $<25$ years, $90.8 \%$ were senior high school or higher degree education graduates, $6.2 \%$ were married, $91.5 \%$ were employed and $59.2 \%$ were having a regular sexual partner.

Data on sexual behaviours of MSM can be seen in Table 2. Over the last month, as many as $70.8 \%$ of respondents were reported to have sex at least with one sexual partner, $52.3 \%$ with at least two partners, and $45.6 \%$ with three sexual partners. The majority of respondents had had insertive sex, $40.0 \%$ with the first sexual partner, $44.6 \%$ with the second sexual partner and $43.2 \%$ with the third sexual partner. A total of $28.5 \%$ of respondents had had receptive sex with the first sexual partner, $34.6 \%$ with the second sexual partner, and $33.6 \%$ with the third sexual partner. In addition, as many as $30.0 \%$ of respondents had had versatile sex with the first sexual partner, $18.5 \%$ with the second sexual partner, and $22.4 \%$ with the third sexual partner.

\section{Table 1 Sociodemographic characteristics of respondents}

\begin{tabular}{lcc}
\hline Characteristics & $\mathbf{n}$ & \% \\
\hline Age & & 53.1 \\
$\quad<25$ years & 69 & 40.0 \\
$25-34$ years & 52 & 6.9 \\
$>34$ years & 9 & \\
Education & & 9.2 \\
$\quad$ Primary, junior high & 12 & 90.8 \\
$\quad$ Senior high and higher degree & 118 & \\
Marital status & & 92.0 \\
$\quad$ Not married & 121 & 6.1 \\
Married & 8 & 1.8 \\
Not answered & 1 & \\
Employment & & 91.5 \\
Employed & 119 & 6.2 \\
Unemployed & 8 & 100.0 \\
Regular sexual partner & & 59.2 \\
Yes & 77 & 40.8 \\
No & 53 &
\end{tabular}


Table 2 Sexual behaviours of respondents

\begin{tabular}{|c|c|c|c|}
\hline Variables & $\begin{array}{c}\text { First sexual } \\
\text { partner } \\
\text { n (\%) }\end{array}$ & $\begin{array}{c}\text { Second sexual } \\
\text { partner } \\
\text { n (\%) }\end{array}$ & $\begin{array}{c}\text { Third sexual } \\
\text { partner } \\
\text { n (\%) }\end{array}$ \\
\hline \multicolumn{4}{|c|}{ Sexual intercourse (in the last month) } \\
\hline Yes & $92(70.8)$ & $68(52.3)$ & $57(45.6)$ \\
\hline No & $38(29.2)$ & $62(47.7)$ & $68(54.4)$ \\
\hline \multicolumn{4}{|c|}{ Sexual role (in the last month) } \\
\hline Insertive & $52(40.0)$ & $58(44.6)$ & $54(43.2)$ \\
\hline Receptive & $37(28.5)$ & $45(34.6)$ & $42(33.6)$ \\
\hline Versatile & $39(30.0)$ & $24(18.5)$ & $28(22.4)$ \\
\hline Missing & $2(1.5)$ & $3(2.3)$ & $1(0.8)$ \\
\hline \multicolumn{4}{|c|}{ Condom use (in the last six months) } \\
\hline Consistent & $88(67.7)$ & $91(70.0)$ & $91(72.8)$ \\
\hline Inconsistent & $38(29.2)$ & $25(19.2)$ & $25(20.0)$ \\
\hline Missing & $4(3.1)$ & $14(10.8)$ & $9(7.2)$ \\
\hline \multicolumn{4}{|c|}{ STIs history of sexual partner (in the last six months) } \\
\hline Yes & $20(15.4)$ & $4(3.1)$ & $5(4.00)$ \\
\hline No & $109(83.9)$ & $125(96.2)$ & $119(95.2)$ \\
\hline Not answered & $1(0.7)$ & $1(0.7)$ & $1(0.8)$ \\
\hline Total & $130(100.0)$ & $130(100.0)$ & $125(100.0)$ \\
\hline
\end{tabular}

Table 3 Sexual partnership patterns

\begin{tabular}{|c|c|c|}
\hline \multirow[b]{2}{*}{ Variables } & \multicolumn{2}{|c|}{ Sexual partnership pattern (in the last year) } \\
\hline & $\begin{array}{c}\text { Concurrent partnership } \\
\text { n (\%) }\end{array}$ & $\begin{array}{c}\text { Monogamous partnership } \\
\text { n (\%) }\end{array}$ \\
\hline Sexual partnership patterns & $93(71.5)$ & $37(28.5)$ \\
\hline \multicolumn{3}{|l|}{ Age } \\
\hline$<25$ years & $35(62.5)$ & $21(37.5)$ \\
\hline $25-34$ years & $47(75.8)$ & $15(24.2)$ \\
\hline$>34$ years & $11(91.7)$ & $1(8.3)$ \\
\hline \multicolumn{3}{|l|}{ Sexual network density } \\
\hline 2-3 partners & $72(69.2)$ & $32(30.8)$ \\
\hline 4-6 partners & $21(80.8)$ & $5(19.2)$ \\
\hline \multicolumn{3}{|l|}{ Sexual role } \\
\hline Insertive & $29(72.5)$ & $11(27.5)$ \\
\hline Receptive & $19(73.1)$ & $7(26.9)$ \\
\hline Versatile & $45(70.3)$ & $19(29.7)$ \\
\hline
\end{tabular}

Table 4 Selective mixing by age

\begin{tabular}{|c|c|c|c|c|c|c|c|c|c|}
\hline \multirow[b]{2}{*}{ Age } & \multicolumn{3}{|c|}{$\begin{array}{c}\text { First sexual partner } \\
n(\%)\end{array}$} & \multicolumn{3}{|c|}{$\begin{array}{c}\text { Second sexual partner } \\
\text { n (\%) }\end{array}$} & \multicolumn{3}{|c|}{$\begin{array}{l}\text { Third sexual partner } \\
\text { n (\%) }\end{array}$} \\
\hline & $<25$ & $25-34$ & $>34$ & $<25$ & $25-34$ & $>34$ & $<25$ & $25-34$ & $>34$ \\
\hline$<25$ & $27(48.2)$ & $21(37.5)$ & $8(14.3)$ & $32(57.1)$ & $18(32.1)$ & $6(10.7)$ & $26(46.3)$ & $24(42.6)$ & $6(11.1)$ \\
\hline $25-34$ & $29(46.8)$ & $27(43.6)$ & $6(9.7)$ & $30(48.4)$ & $20(32.3)$ & $12(19.4)$ & $25(39.0)$ & $29(45.8)$ & $10(15.3)$ \\
\hline$>34$ & $3(25.0)$ & $5(41.7)$ & $4(13.3)$ & $9(75.0)$ & $1(8.3)$ & $2(16.7)$ & $7(58.3)$ & $4(33.3)$ & $1(8.3)$ \\
\hline
\end{tabular}




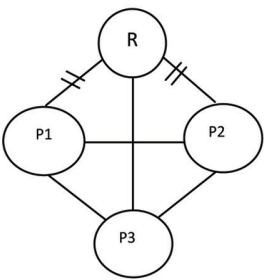

$5(3.9 \%)$

Two sexual interactions

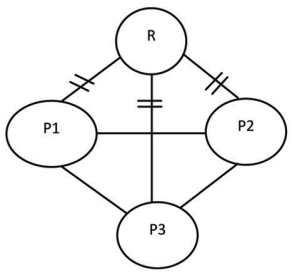

$99(76.2 \%)$
Three sexual interactions

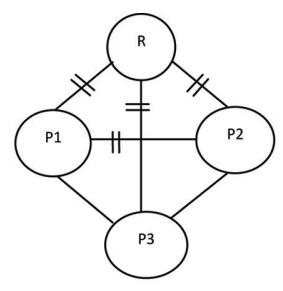

$20(15.4 \%)$ Four sexual interactions

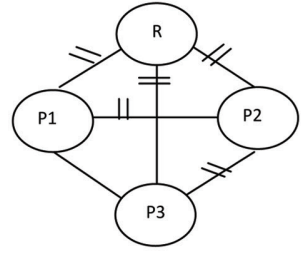

$5(3.9 \%)$

Five sexual interactions

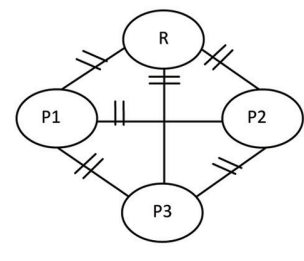

$1(0.8 \%)$

Six sexual interactions

Figure 1 Density of sexual network (in the last year)

The consistent condom use in the last six months were reported by $67.7 \%$ of respondents with their first sexual partner, $70.0 \%$ with the second sexual partner, and $72.8 \%$ with the third sexual partner. The majority of MSM reported that they were not aware of their partner STIs history in the last year which were $83.9 \%$ for the first sexual partner, $96.2 \%$ for the second sexual partner, and $95.2 \%$ for the third sexual partner.

Sexual network density can be seen in Figure 1, where ' $\mathrm{R}$ ' is respondents, 'P1' is the first sexual partner, 'P2' is the second sexual partner, and 'P3' is the third sexual partner. Sexual partnership and interactions between respondents and their sexual partners were indicated by ' $=$ '. The more frequent sexual partnerships and interactions between respondents and their sexual partners indicates a higher density of sexual network. Figure 1 shows that as many as $76.2 \%$ respondents reported that they had three sexual interactions in the last year, 3.9\% had two sexual interactions, $15.4 \%$ had four sexual interactions, 3.9\% had five sexual interactions, and $0.8 \%$ had six sexual interactions.

Sexual partnership of respondents can be seen in Table 3. As many as $71.5 \%$ of respondents were having concurrent partnership while $28.5 \%$ were having monogamous partnership. The older MSM tended to have higher concurrent partnership when compared to the younger MSM, for example among MSM age $<25$ years around $62 \%$ were having concurrent sexual partnership, while among age groups of 25-34 years and $>35$ years were $75.8 \%$ and $91.7 \%$ respectively. The concurrent sexual partnership with 2-3 partners was $69.2 \%$, while with 4-6 partners was $80.8 \%$. The majority of MSM who had concurrent sexual partnership

were varied in their sexual role with $72.5 \%$ were insertive, $73.1 \%$ were receptive, and $70.3 \%$ were versatile.

Sexual network of respondents based on age can be seen in Table 4. It displays the selective mixing among respondents. It can be observed that younger respondents tended to choose sexual partner within their age group for the first, second, or third sexual partners. In contrast, older respondents tended to find younger sexual partners.

\section{DISCUSSION}

This study showed that the consistent condom use among MSM population was relatively high along with a high sexual network density and concurrent sexual partnership. Finding from this study in relation to sexual network density and sexual behaviour is relatively consistent with other study conducted in 2012 in three big cities of Medan, Jakarta and Bali. ${ }^{7}$ It found that as many as $43.9 \%, 15.9 \%$, and $37.8 \%$ MSM population in Bali were having 1-5, $6-10$, and $>10$ sexual partners respectively. ${ }^{7}$ There are several methodological differences between the present study and their study ${ }^{7}$ which are different study locations and sampling methods. In the present study, samples were selected from MSM who accessed STIs services in two clinics in Denpasar and Badung, while in the previous study MSM were recruited from the hotspot points. Furthermore, in the present study, we asked sexual behaviours for only three sexual partners. The previous study found that the consistent condom use for receptive sex in the last year was only $39.2 \%$ and $44.4 \%$ for insertive sexual role. ${ }^{7}$ In contrast, the present study revealed that the consistent condom use in the last six months was between $67.7 \%$ (with the first sexual partner) and $72.8 \%$ (for the second and third sexual partners). However, the present study do not capture consistent condom use based on sexual roles (receptive and insertive). It can be explained that a higher condom use in the present study when compare to the previous study ${ }^{7}$ may be due to the interviewer bias. The present study employed a midwife and a counsellor to interview respondents where more possibility that the reported condom use is overrated by respondents.

In terms of sexual role, the previous study found that as many as $80.4 \%$ of MSM had had insertive sex while $77 \%$ MSM had had receptive sex. ${ }^{7}$ In the present study, as many as $40 \%, 44.6 \%$, and $43.2 \%$ of respondents had had insertive sex with their first, second, and third sexual partners. Furthermore, as many as $28.5 \%, 34.6 \%$, and $33.6 \%$ of respondents had had receptive sex with their first, second, and third partners. Lastly, as many as $30.0 \%, 18.5 \%$, 
$22.4 \%$ of respondents had had versatile sex with their first, second, and third sexual partners. It can be explained that the way of presenting the question about sexual role to respondents influences responses from them.

Studies from other countries also revealed a high sexual network density among MSM population. A study in the US among black Americans between 2013 and 2014 found that respondents who had one, two, $3-5$, and $\geq 6$ sexual partners in the last six months were $20 \%, 24 \%, 42 \%$, and $13 \%$ respectively. ${ }^{4}$ Another study among African Americans in the US showed a lower density of sexual network. It found that MSM who had one, two, three and four sexual partners were 39\%, 23\%, $18 \%$, and $15 \%$ respectively. ${ }^{8}$ A survey in China between 2008 and 2009 found that MSM who had 2-10 and $>10$ sexual partners were $47.4 \%$ and $5.0 \%$ respectively. ${ }^{9}$ The present study found that selective mixing was common among older MSM. Younger MSM tended to find sexual partners in the same group categories while older MSM tended to find younger sexual partners. This phenomenon is also observed in the USA. ${ }^{10}$ This present study revealed that concurrent sexual partnership predominantly reported by older MSM. As many as $91.7 \%, 75.8 \%$, and $62.5 \%$ of respondents who reported concurrent sexual partnership were aged $>35$ years, 25-35 years and $<25$ years respectively. While in the US, concurrent sexual partnership was observed in all age groups which were 18-24 years (24.2\%), $25-29$ years $(27.5 \%), 30-39$ years $(24.7 \%)$, and $>40$ years $(23.6 \%){ }^{10}$

\section{CONCLUSION}

MSM population in Bali seem to have high risk sexual behaviours with great sexual network density, high concurrent sexual partnership, and selective mixing between older and younger MSM population.

\section{ACKNOWLEDGEMENT}

We would like to thank the head of Bali Medica Clinic and the head of Denpasar II Public Health Centre and also all respondents from both clinics who had supported this study.

\section{REFERENCES}

1. Ministry of Health of Indonesia. 2012 Size Estimation of Key Affected Populations (KAPs). Jakarta; 2013.

2. Ministry of Health of Indonesia. Fact Sheet Survei Terpadu Biologis dan Perilaku LSL tahun 2007 dan 2011. Jakarta; 2011. [Fact Sheet, Integrated Biological and Behaviour Survey among MSM in 2007 and 2011. Jakarta; 2011].

3. Kerti Praja Foundation. Laporan Bulanan Klinik Amerta Yayasan Kerti Praja-Implementing Unit SSR [Monthly report Amerta Clinic Kerti Praja Foundation Implementing Unit SSR]. Denpasar: YKP; 2017.

4. Ma Q, Zeng S, Xia S, et al. Risky sexual networks and concentrated HIV epidemics among men who have sex with men in Wenzhou, China: a respondent-driven sampling study. BMC Public Health;2015; 15: 1246.

5. Tucker JS, Hu J, Golinelli D, Kennedy DP, Green HD, Wenzel SL. Social Network and Individual Correlates of Sexual Risk Behavior Among Homeless MSM Youth; 2012; 51: 386-392.

6. Praptoraharjo I, Subronto YW, Nanwani ST. Sexual Network of Young MSM in Indonesia; 2013; 2013: 1-8.

7. Grierson J, Mcnally S, Hidayana I. Networks of MSM in Indonesia : A 2-mode study of MSM and sites of engagement Networks of MSM in Indonesia : A 2-mode study of MSM and sites of engagement; 2013; 1-180.

8. Peterson JL, Rothenberg R, Kraft JM, et al. Perceived condom norms and HIV risks among social and sexual networks of young African American men who have sex with men. Health Educ Res; 2009; 24: 119-127.

9. Zhang D, Bi P, Lv F, et al. Changes in HIV prevalence and sexual behavior among men who have sex with men in a northern Chinese city: 2002-2006. J Infect; 2007; 55: 456-463.

10. Tieu HV, Liu TY, Hussen S, et al. Sexual networks and HIV risk Among Black men who have sex with men in 6 U.S. cities. PLoS One; 2015; 10: 1-18.

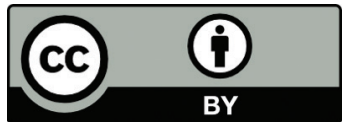

This work is licensed under a Creative Commons Attribution 